\title{
Cancer Pain Management
}

National Cancer Institute

\section{Source}

National Cancer Institute. Cancer Pain Management. NCI Thesaurus. Code C15633.

Therapy directed toward reduction and control of cancer pain. 